\title{
WHAT Might A FiELd ARCHAEOLOGIST WANT FROM AN ARCHITECTURAL 3D MODEL?
}

\author{
FEDERICO BUCCELLATI \\ GOETHE UNIVERSITÄT - FRANKFURT AM MAIN, GERMANY
}

3D modeling of architecture has become more and more sophisticated over the last three decades. The aim of this development has been primarily to increase the visual quality of the final model, both in terms of the number of polygons which define a surface as well as the resolution and quality of the textures applied to these surfaces; additionally, the space in which the model is placed also becomes more complex, including such elements as atmospheric condition modeling. This sophistication has resulted, as a necessary and understandable consequence, in the fact that the creation of $3 \mathrm{D}$ models has become a more complicated process, and requires special training-universities today offer both undergraduate and graduate-level degrees in 3D modeling.

Thus the common practice in archaeology is for a field archaeologist to get a professional company or a team from a university technology department to come to the excavation and produce a model. Normally they come to the excavation for a few days or a week, collecting data; then they produce a very detailed model, using the latest software and/or hardware. The end-result of such a model, for the archaeologists, is often a collection of $2 \mathrm{D}$ JPEG images, and perhaps a film clip showing a walk-through. ${ }^{1}$

${ }^{1}$ I am not laying blame here at the feet of the IT departments- the application of $3 \mathrm{D}$ programs to archaeological projects has been very 
What value does this have for the archaeological project? The primary value of this result is in communication, where the still images can be used as slides, printed out and shown at the site or used in publications. The walk-through in particular can also be quite useful in a didactic setting, giving the possibility to demonstrate the impact of the architecture on a visitor or spectator. ${ }^{2}$ This is certainly a laudable goal, and some wonderful projects have been published and made available to a wider audience; furthermore, some very interesting work has been done on thematic and visual relationships vis-à-vis architecture and decoration.

However, there is a growing problem regarding the relationship between the field archaeologist and these 3D models: that of interactivity. It is quite difficult for the archaeologist to interact with the 3D model itself: first, the hardware required to run the necessary software can be quite expensive, and difficult to set up. While the 3D modeling team gives a copy of the model itself to the archaeologists, the software used to view the model is often quite expensive and runs only on high-end computer systems. The second hurdle for an archaeologist is that the software used is quite complex, and therefore opening, manipulating and exporting portions or new images of the model requires a big investment in time to learn to use the software.

Thus a metaphor I like to use for this situation is that of a UFO visit: a team whose skills are nearly incomprehensible to the locals arrives, collects a lot of data and asks a lot of questions, then after few days departs, never to be heard from again, leaving a nearly magical final product behind. How this product came to be

limited, both within the classroom environment as well as in the field (Forte, 'Virtual Archaeology'). The fact that the programs used were originally designed for illustration tends to influence the product of such work as well (Frischer, 'Introduction: From Digital Illustration'), while the choice behind the types of illustration should instead be guided by the purpose of the illustration itself (Frankland, 'A CG Artist's Impression').

${ }^{2}$ For more see Lock, Using Computers in Archaeology, pp. 152-4 and Micale, "From Drawing to Vision". 
is unclear to the 'locals', and its use is very limited vis-à-vis the functionality it would have in the hands of one of the 'aliens'.

This is of course an oversimplified 'tongue-in-cheek' analogy for what goes on, but it serves to highlight the problems: the lack of long-term interaction between the modeling team and the archaeologists, and the lack of understanding as to how to manipulate the final product and use all of its potential within the archaeological process.

\section{The Problem of InTERaCtion: Archaeology and 3D TECHNOLOGY}

This want of long-term interaction between the archaeologists and the modelers is worth exploring more in depth: three main points of difference are responsible for this lack of interaction: accuracy, didactics and stratigraphy.

\section{Accuracy}

Computer scientists and model builders look primarily for accuracy in terms of verisimilitude in the model. This often leads to a great deal of energy invested in applying textures which most resemble the material present in the excavation. Accuracy for the archaeologist does not mean visible verisimilitude, but rather measurable precision. This means that the corners of walls, rabbeting and floors must be represented as less than 90 degrees, jagged or uneven, if that is what is present in the archaeological record. All too often these uneven lines present in the excavation are often 'corrected' in a 3D model - the tops of walls in the archaeological record, for example, which are almost always jagged, curved or sloping, are represented as flat level surfaces, if not directly reconstructed to a 'standard' height. Concisely, the 3D modeler aims at 'visual' accuracy, while the archaeologist wants 'measurable' accuracy. 


\section{Use of the Model}

The second difference in perspective between the 3D modeler and the archaeologist is the question of the use of the model. ${ }^{3}$ The $3 \mathrm{D}$ modeler often aims to represent the building as a reconstruction of what it probably looked like. The archaeologist, on the other hand, wants a model to show both the building as it was found and the specific context, either with other buildings, or with the material found within the building, or to compare the perception of volumes between this and another building's 3D model. Thus, what the 3D modeler sees as a finished, architectural product as a 'singular perfection', the archaeologist sees as the central and original building block to which other data must be added. 3D qua reconstruction is a case in point: the $3 \mathrm{D}$ modeler wants to know from the archaeologist 'how things were' to create a single final model, while the archaeologist is interested in using the model as a tool to see and compare different reconstruction possibilities, all of which are possible. Such different possibilities lead to scholarly discussions which improve not only the model but our understanding of the past as well. ${ }^{4}$

\section{Stratigraphy: The Fourth Dimension}

Finally, the 3D modeler sees a building with the eyes of an architect, looking at a frozen three dimensional object, executed as

${ }^{3}$ For an interesting overview of the various uses of a 3D model, see the discussion in Wittur, Computer-Generated 3D-Visualisations, pp. 15-9). Some of the most transformed models (in meaning and in architecture) can be found in computer games (Gardner, 'The Past as Playground'). Micale also makes the case for 3D models as a means of 'experiencing' architecture, but warns also of the danger of using reconstructions in the stead of archaeological data (Micale, 'From Drawing to Vision').

${ }^{4}$ One of many examples of this scholarly dimension is Johanson and Frischer's work with the Sanctuary of the Sun in modern Bolivia (Frischer and Johanson, 'A Digital Model of the Inca Sanctuary'). One of the earliest books made for a wider audience which included explanations of the scholarly value of 3D models was published in 1997 (Forte and Siliotti, Virtual Archaeology). 
planned. 5 The archaeologist, however, looks at a building and sees a process of use over time, the buildup of stratigraphic evidence in the building showing the changing functions of rooms and installations. The element of time can be very difficult to introduce into a model, in part because the programs used are not designed to include time as a dimension: the very definition of a CAD program is that it produces a single frozen model. One particularly successful attempt was the 3D model of ancient Troy produced for the exhibit "TROIA-Traum und Wirklichkeit" which included a slider designed to allow the user to change the model based on the chosen time period ("TROIA Traum und Wirklichkeit" 2013; "Troia VR" 2013). The project was, however, only possible through the intense collaboration throughout the modeling process between the archaeologists and the modelers. Another example is the work of $\mathrm{U}$. Lieberwirth with data from the Akroterion excavations which uses the GRASS software to analyze stratigraphic volumes. ${ }^{6}$

\section{Desiderata $^{7}$}

With the problem now defined, the question remains: what elements might be changed in order to better serve the needs of a field project? The following seven desiderata cover, on a general

${ }^{5}$ Even Zevi's insistence on the four-dimensions of architecture does not really encompass what the archaeologist sees; Zevi's four-dimensions are limited to the experience of a visitor moving through a building over minutes or hours, and not the changes a building goes through over years (Zevi, Architettura in nuce, pp. 47-51).

${ }^{6}$ Lieberwirth, 'Voxel-Based 3D GIS'.

${ }^{7}$ I use the term 'desiderata' here, hopefully correctly, in the sense of 'a collection of those points which I have found lacking in some applications of 3D models'. See Fowler's amusing entry regarding 'desiderate'- "desiderate (feel the want of, 'think long for') is a useful word in its place, but is so often misplaced that we might be better without it..." (Fowler and Gowers, A Dictionary of Modern English Usage, p. 126). 
level, what an active field project ${ }^{8}$ needs from a 3D model. The aim of this portion of this paper is to discuss the reasons behind the needs for these desiderata, so that a field project with limited experience in dealing with 3D models can approach the technology, and those who are experts in using it, with a real aim of integrating the results into their research project.

\section{Precision in reflecting the actual archaeological record}

The 3D model must reflect the actual archaeological record-the structure as found. Ideally, this means that the model would be constructed of 3D solid shapes, so that the volumes of the archaeological record are present as volumes in the model. The 'inconsistencies' of the archaeological record should be present in the model as well, both in terms of 'inconsistencies' in the ancient architecture as well as the damage that the building has suffered over time.

Ancient buildings often seem to follow an 'ideal' architectural layout (square corners, even rabbeting, etc.), but the reality of the architectural record sometimes is at variance with what one would expect from such an ideal plan. This variance is of great interest to the study of the archaeological record, and in fact 3D models can be of great use in identifying these differences which might otherwise escape a mere visual inspection.

What is being modeled is not a building, but is a ruin. Thus the architectural plan has been affected by later incursions such as pits or foundation cuts. These man-made elements alter, sometimes drastically, the architecture 'as found' as opposed to the footprint one can extrapolate from the building's architectural lines. In addition, buildings near the surface of archaeological sites are often damaged by natural causes, such as seasonal streams (wadis) or the undercutting of rivers which change their course over time. These natural phenomena also change the building, leaving an

8 Were the model being built for a project which was no longer being excavated some of these 'desiderata' might be different, but in general the points would still hold. 
archaeological record which reflects only in part the structure to be understood as a complete architectural complex.

\section{Use, as much as possible, data already collected in the field}

It can be useful to use data already being collected during the normal course of excavations. Time in the field is always at a premium, and if a system can employ the data already collected in the normal course of archaeological documentation of a site, then it is more likely that this data will be collected on a regular basis.

There is a further advantage in using data that is already being collected: the integration into current excavation strategies and the applicability to older datasets. If the data is collected on a regular basis because it is part of the archaeological documentation, then it is more likely that the $3 \mathrm{D}$ model will also be generated on a regular basis and integrated into the decision-making process which guides excavation strategy. ${ }^{9}$ Furthermore, the use of data normally collected (in as far as possible) means that older datasets from excavations which did not explicitly document for a 3D model can still be used to create $3 \mathrm{D}$ visualizations.

Often there are newer technologies which allow for a more rapid collection of measurements, but one needs to take into consideration the fact that such systems may have 'hidden' disadvantages: some are not necessarily available for the duration of the whole excavation period, while others may not be easy enough for several staff members to learn to use effectively. Also, the data from specialized equipment may need long postprocessing times, so that the actual collection of data is very fast and extremely accurate, but the time it takes to extrapolate absolute (or site-relative) coordinates from the initial data takes considerably longer.

Thus an excavation that measures the wall corners in a unified local grid system and measures the elevations of wall-tops and floor levels, already has almost all of the data needed to create a model.

\section{0.}

9 See also Buccellati and Kelly-Buccellati, Mozan 1: The Soundings, p. 


\section{Have the results available in a lasting format}

To insure the durability of the data, it is important that what is collected in the field be conserved in a format that will be legible and useful to archaeologists and modelers long after the programs we use today have gone out of use. Too often wonderful projects are lost to posterity because the program used to create them no longer exists, or have changed to the extent that they no longer open older files adequately. ${ }^{10}$ Just to name a few examples: Access 98 files which can be opened only partially with later versions of the program, or older DOS programs like Reflex or Lotus 1-2-3 (precursors of spreadsheet programs), Fontasy (a precursor of layout programs like InDesign) or QuickBasic (one of the first nested programming languages). In a field where one of the most important sources are the texts discovered through archaeology, it seems incongruous that some of the tools we use to document that record have such short lifespans. ${ }^{11}$

\section{Allow for the integration of stratigraphy as well as architecture}

Ideally, the models produced in and for an archaeological project should not be limited to the reconstruction of architecture, but should also allow for the possibility that the user would want to reflect stratigraphic relationships. The ability to integrate diverse construction phases, different types of accumulations and the findspots of objects are all fundamental elements in the archaeologist's understanding of the archaeological record, and as such should be planned for in the building of models which reflect that record.

Seldom are the buildings found in an archaeological excavation built in a single moment and used uniformly over time

10 As opposed to physical 3D models, which are preserved as documents of their time and the buildings that they represent; see for example Oechslin's article on 3D models from the Renaissance (Oechslin, 'Architekturmodell: 'Idea materialis").

${ }^{11}$ For a discussion of archaeological publishing in general vis-à-vis open standards and data perseverance, see Kansa, Whitcher Kansa and Watrall, Archaeology 2.0: New Approaches. 
for a single set of functions-it is rather the case that the structures found in an excavation were built over a period of time, showing differences in construction techniques. Later activity in the building might have different architectural needs, so a doorway might be modified or light sources added or blocked. A model which is designed to reflect a building discovered in an archaeological context should reflect those differences.

Within the structures uncovered (as well as in the open spaces within the urban texture, for that matter) a series of accumulations reflect the use over time of a structure, including layers of abandonment and structural collapse. Here too, the model should be designed to reflect not only the constructed elements, but also the accumulations which reflect their use over time.

The model would then contain volumes which define architectural elements but also define stratigraphic volumes just as well. By integrating both in a single model over several layers, it is possible to visualize not only the constructed space with all of its modifications, but also these patterns of use as present in the accumulations found within.

\section{Allow for the inclusion of objects}

In addition to the stratigraphic elements, the model should also allow for the inclusion of objects, so that studies such as distribution analyses can be carried out hand-in-hand with a model which reflects the architectural/stratigraphic situation. The moveable and immovable finds in an excavation are, obviously, inexorably linked - and this connection should also be planned for in a model. Precisely the connection between architecture, stratigraphic elements and the distribution of objects and pottery within them is the foundation for all archaeological interpretation; thus the models built should reflect those relationships in order to aid in archaeological research and communicate the results of said research. Thus the model becomes not only a way of visualizing an ancient structure, but a way of exploring the multiplicity of 
relationships present in an excavation, ${ }^{12}$ with the aim of providing a supporting argument for a proposed line of interpretation.

\section{Allow for change and expansion of the data}

The model should be easily manipulated, allowing for incremental change in the model as the understanding of the archaeological record grows or is added to through further excavations. A model such as the one I am proposing should not be 'planned for' when the excavation of a structure is 'finished'. First of all, an archaeological model is nearly never 'finished', as it is seldom that a structure is completely excavated, and even if all the walls have been uncovered, a model could always add something more, including more of the ancient urban texture or through the definition of earlier, underlying layers. Furthermore, the idea that the model is to be generated after the archaeological excavationand concomitant development of interpretations - runs contrary to the ideas proposed in this paper.

Thus the model should be designed from the beginning to be incomplete- thereby planning also for the integration of data to be added at a later date, as uncovered through further excavations. ${ }^{13}$

This has the fortuitous byproduct of producing a model which can be modified to reflect several different possible reconstructions. If the base model can be easily modified with further excavations, then several different versions of the model could be generated in order to compare diverse reconstructions.

\section{Allow for the inclusion of the model in other programs}

Finally, the model should be in a data format which can be imported into other programs. While the model can be

12 The most recent monograph to highlight the importance of such relationships in an archaeological context is Hodder, Entangled: An Archaeology of the Relationships.

13 This emphasis on adaptability is also highlighted in M. Shanks article on digital media, in which he refers to the Agile Manifesto for software (see www.agilealliance.org), which holds as one of its tenets the flexibility of the software product (Shanks, 'Digital Media, Agile Design'). 
manipulated within AutoCAD itself, many functions one might need for visualization or analysis are not available. GIS, animation and interaction are three areas where the use of the generated 3D model could be used to understand and communicate the archaeological record, and are little developed in AutoCAD, which is designed primarily for the architectural design.

GIS programs allow for the integration of several different datasets such as satellite imagery or GPS terrain models, and can be of great use in sitewide analysis as well as on the macro- and microregional levels. ${ }^{14}$ QGIS, Grass and SIG are open-source GIS variants which have been used in the field alongside the market leader, ArcGIS.

Animation can be of great use when the model is meant to communicate architectural volumes; the movement of the model mimics how one perceives a structure by walking near and in it. ${ }^{15}$ Blender is the most common open source program used for animation, while Maya and Studio Max are two commercial programs for Windows which are both owned by Autodesk, the same company which makes AutoCAD - thus they have a vested interest in ensuring cross-program compatibility.

Interactive programs allow users to explore the architectural space as an experienced environment. The programs available for such a deployment of the model vary widely; two particularly interesting examples are SecondLife and CaveUT.

\section{CONCLUSION}

The aim of this paper has been to point out some of the lessons learned by an archaeologist in dealing with a 3D model - not that these points should be seen as necessary for every project, but in the hope that by discussing some of the points of divergence between the approaches of 3D modelers and the needs of

14 A great deal has been written about the integration of GIS in archaeology, for two discussions of vertical integration, see Piro, 'Archaeologia e formazione' and Forte, I sistemi informativi geografici.

15 For more on perception see Buccellati, '3-D Rendering and Animation' and Buccellati, 'The Monumental Temple Terrace at Urkesh'. 
archaeologists, a clearer definition of goals from the beginning of such a working relationship can be achieved.

\section{BIBLIOGRAPHY}

Buccellati, F 1998, '3-D Rendering and Animation at Tell Mozan/Urkesh', in G. Buccellati (ed.), Urkesh and the Hurrians: Studies in Honor of Lloyd Cotsen (Bibliotheca Mesopotamica 26), Malibu, pp. 53-64. 2010, 'The Monumental Temple Terrace at Urkesh and its Setting', in J Becker, R Hempelmann, and E Rehm (eds), Kulturlandschaft Syrien: Zentrum und Peripherie Festschrift für JanWaalke Meyer (AOAT 371), Münster, pp. 71-86.

Buccellati, G and Kelly-Buccellati, M 1988, Mozan 1: The Soundings of the First Two Seasons (Bibliotheca Mesopotamica 20), Malibu. Forte, M 2002, I sistemi informativi geografici in archeologia, Rome.

2008, 'Virtual Archaeology: Communication in 3D and Ecological Thinking', in B Frischer and A Dakouri-Hild (eds), Beyond Illustration: $2 D$ and 3D Digital Technologies as Tools for Discovery in Archaeology, Oxford, pp. 21-35.

Forte, M and Siliotti, A (eds) 1997, Virtual Archaeology: Great Discoveries Brought to Life through Virtual Reality, London.

Fowler, H W and Gowers, E 1985, A Dictionary of Modern English Usage, Oxford.

Frankland, T 2012, 'A CG Artist's Impression: Depicting Virtual Reconstructions Using Non-Photorealistic Rendering Techniques', in A Chrysanthi, P Murrieta Flores and C Papadopoulos (eds), Thinking beyond the Tool: Archaeological Computing and the Interpretive Process, Oxford, pp. 24-39.

Frischer, B 2008, 'Introduction: From Digital Illustration to Digital Heuristics', in B Frischer and A Dakouri-Hild (eds), Beyond Illustration: $2 D$ and 3D Digital Technologies as Tools for Discovery in Archaeology, Oxford, pp. v-xxiv.

Frischer, B and Johanson, C 2008, 'A Digital Model of the Inca Sanctuary of the Sun', in B Frischer and A Dakouri-Hild (eds), Beyond Illustration: $2 D$ and $3 D$ Digital Technologies as Tools for Discovery in Archaeology, Oxford, pp. 106-10.

Gardner, A 2007, 'The Past as Playground: The Ancient World in Video Game Representation', in T Clack and M Brittain (eds), Archaeology and the Media, Walnut Creek, pp. 255-72 
(http://public.eblib.com/EBLPublic/PublicView.do?ptiID=6 77757).

Hodder, I 2012, Entangled: An Archaeology of the Relationships between Humans and Things. 1, West Sussex.

Kansa, E, Whitcher Kansa, S and Watrall, E (eds) 2011, Archaeology 2.0: New Approaches for Communication and Collaboration, Los Angeles.

Lieberwirth, U 2008, 'Voxel-Based 3D GIS: Modelling and Analysis of Archaeological Stratigraphy', in B Frischer and A Dakouri-Hild (eds), Beyond Illustration: 2D and 3D Digital Technologies as Tools for Discovery in Archaeology, Oxford, pp. 8594.

Lock, G 2003, Using Computers in Archaeology: Towards Virtual Pasts, London.

Micale, M G 2007, "From Drawing to Vision'. The Use of Mesopotamian Architecture Through the Construction of Its Image', in W. Boerner and S. Uhrliz (eds), Cultural Heritage and New Technologies, Vienna.

Oechslin, W 2011, 'Architekturmodell: 'Idea materialis", in W. Sonne (ed.), Die Medien der Architektur, München, pp. 131-55.

Piro, S 2011, 'Archaeologia e formazione: technologie di rilievamento, interpretazione e rappresentazione', in S. Alaura and A.L. D'Agata (eds), Quale futuro per l'archeologia?, Gangemi, pp. 61-74.

Shanks, M 2007, 'Digital Media, Agile Design and the Politics of Archaeological Authorship', T Clack and M Brittain (eds), Archaeology and the Media, Walnut Creek, pp. 273-89.

“TROIA Traum und Wirklichkeit." 2013. Accessed April 30. http://www.troia.de/pages/portal.php.

"Troia VR." 2013. Accessed April 30. http://www.unituebingen.de/troia/vr/index.html.

Wittur, J 2013, Computer-Generated 3D-Visualisations in Archaeology: Between Added Value and Deception, Oxford.

Zevi, B 1972, Architettura in nuce, Firenze. 